\title{
The Design Scheme and Efficiency Analysis on Energy Conversation of Existing Residential Buildings in Changchun City
}

\author{
LIN Mang ${ }^{1, a}$ \\ 1 Jilin Jianzhu University, Changchun 130000,China \\ a LinMang2013@yeah.net
}

Keywords: Energy sources; Energy-saving; Stability; Building energy conservation; energy consumption; existing buildings

\begin{abstract}
Nowadays, world energy source has become a lifeline of national economic development and national security. Although China is abundant in energy sources, the per capita are far lower than the world average level, making energy situation serious. Energy consumptions conclude industrial energy consumption, transportation energy consumption and Building energy consumption. With the rapid development of economy in our country, the growth of the building energy consumption has been increasing obviously. Energy tension and the resulting environmental problems are the top issues our country facing with. Now existing building areas are about 42 billion square meters in China, 90\% existing buildings of which are built in the last eighty and ninety century. [2] And those old buildings have features of simple retaining structure design, big doors and windows gaps, poor air tightness, residential thermal environment, building insulation and thermal insulation, low level of building energy efficiency, and less energy saving measures as well. Therefore, whether the energy saving renovation of existing residential buildings will be carried out is the determination of whether the high efficient use of resources and energy sources and sustainable development road can move forward.
\end{abstract}

\section{Introduction}

Chinese existing buildings energy conservation is pushed by the south to north direction. [1] Changchun city of Jilin province is located in the North-East, belongs to cold region. The existing building energy-saving renovation work in Changchun city is an important part of construction energy conservation work in China. Because heating energy consumption accounts for the proportion of building energy consumption is as high as $50 \% \sim 60 \%$ in winter, building energy conservation potential is tremendous.[4] As residents higher requirements for the improvement of indoor thermal environment and relevant policies and regulations on energy conservation, the study of existing residential buildings energy-saving renovation will have practical significance.

This paper mainly introduces the design scheme of energy saving conservation of existing residential buildings in Changchun city, and analyzes the effect after energy saving renovation of existing residential building energy-saving buildings.

\section{The Design scheme and effect of energy saving transformation}

The design ways contribute to fulfilling energy conservation for existing residential buildings in Changchun city, as the flow-process diagram A1, such as the existing peripheral residential building insulation, heating pipe network, the indoor heating system, roof structure for energy saving and facade decoration and so on, which can reduce building energy consumption, improve the environment, indoor thermal insulation waterproof effect, beautify the appearance of the building and enhance housing security system. 


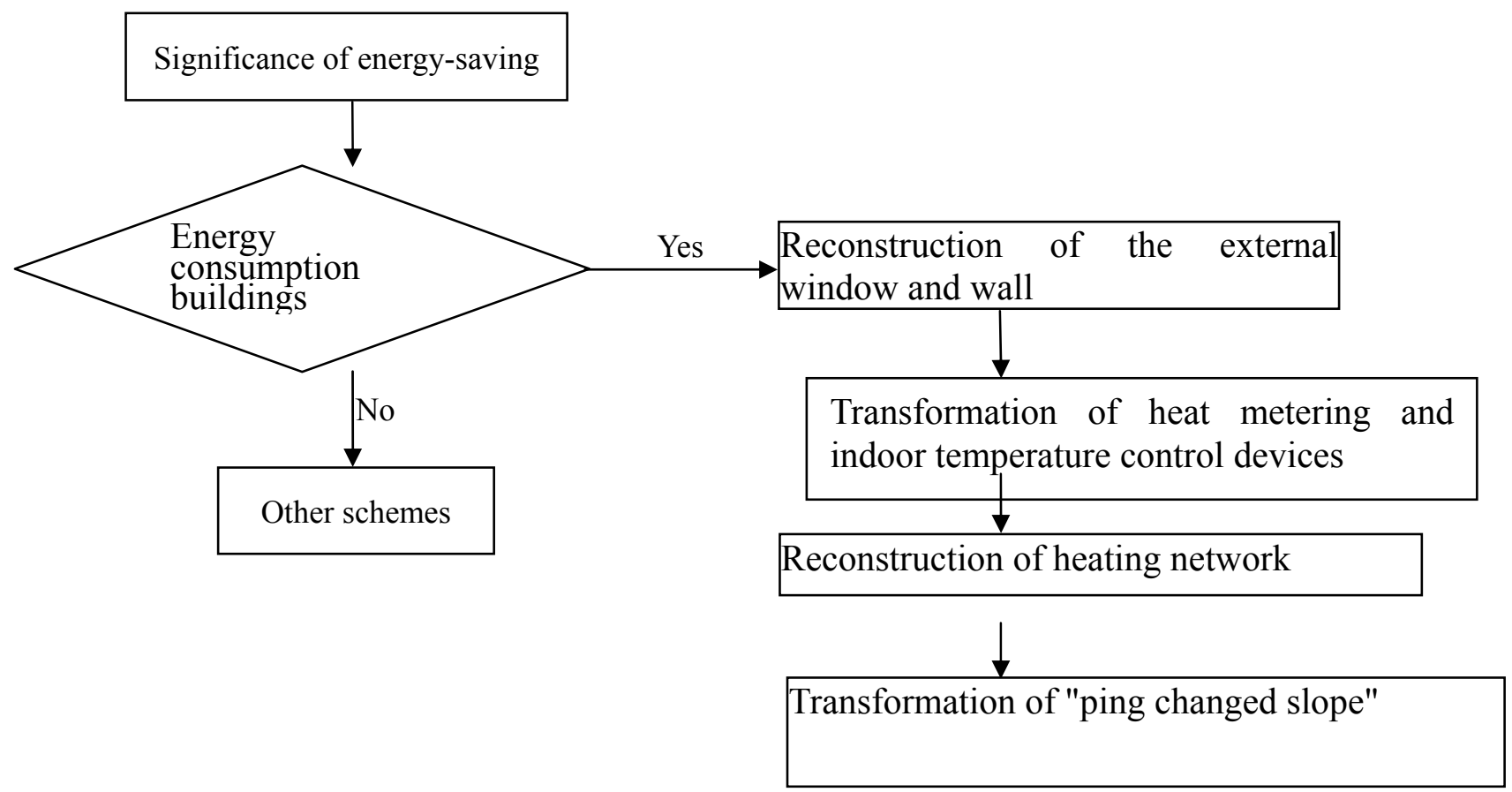

A1

\section{Key factors involved in design}

According to the analysis on examples at home and abroad of energy efficiency retrofit of existing residential buildings, determines the key influence factors. The implementation of both the technical design of residential building energy saving reconstruction measures mainly includes:

\subsection{Reconstruction of the external window}

Energy-saving reconstruction of external window is a kind of more complex work in retaining structure. Original fasting single glass windows have to be changed into a flat double glass broken bridge Aluminum energy-saving windows according to standard design requirements. It mainly contains pasting benzene boards on external walls, replacing them with energy-saving windows and other measures to carry out the energy saving of the retaining structure and improve building thermal insulation properties. After the transformation of retaining structure, it should meet the design standard of building energy-saving residency requirements as much as $50 \%$ [4].

Most of the changing outside windows are push-pull windows, which have the features of poor tightness, window air infiltration, as well as poor quality of construction, poor sealing and opening frame. The whole air tightness of outside windows is below level 1. [1]

In terms of building area of $5000 \mathrm{~m}^{2}$, the annual reduction of dust emissions to the environment is $9.00 \mathrm{t}$, the carbon dioxide is $30.50 \mathrm{t}$, and the sulfur dioxide is $0.92 \mathrm{t}$. [3]

The values of coefficient of heat conductivity $(\mathrm{K})$ and thermal inertia (D) have to meet the demands of the standard in chart A2.[5]

A2.The limited value of $\mathrm{K}\left(\mathrm{K}\left[\mathrm{W} /\left(\mathrm{m}^{2} \cdot \mathrm{K}\right)\right]\right)$ and $(\mathrm{D})$

\begin{tabular}{|c|c|}
\hline External wall & Outside of building \\
\hline $\mathrm{D}>2.5, \mathrm{~K} \leqslant 1.5$ & $\mathrm{D}>2.5, \mathrm{~K} \leqslant 1.0$ \\
\hline
\end{tabular}




\subsection{Reconstruction of the external wall}

Taking top buildings as an example, after walls reconstruction, building roof surface temperature decreased obviously in summer, which played a good thermal insulation, while building roof surface temperature is significantly lower than those in existing buildings in winter, which plays a better role in keeping temperature and humidity. Therefore, this kind of reconstruction improves living comforts.

In terms of building area of $5000 \mathrm{~m}^{2}$, only adding light steel structure slope roof modification can reduce dust emissions to the environment for $2.25 \mathrm{~T}$, the carbon dioxide for $7.63 \mathrm{~T}$, and sulfur dioxide for $0.23 \mathrm{~T}$ in a whole year. [3] A3. [5]

Heat consumption index of buildings after reconstruction should be lower that the value in chart

$$
\text { A3. }\left(\mathrm{W} / \mathrm{m}^{2}\right)
$$

\begin{tabular}{|c|c|c|c|}
\hline$\leq 3$ floors & $(4 \sim 8)$ floors & $(9 \sim 13)$ floors & $\geq 14$ floors \\
\hline 16.1 & 15.0 & 13.4 & 12.1 \\
\hline
\end{tabular}

\subsection{Transformation of heat metering and indoor temperature control devices}

Installation of heat metering devices in the heating system provides the conditions for the heating charge according to quantity system. Installation of temperature control devices also gives chances to user controlling their room temperature and saving heating energy consumption. Installation of energy-saving device, improving the heating quality and efficiency, reduces heating energy consumption.

Al1 the target efficiency ratio of changing air conditioner after reconstruction should be higher than the one showed in chart A4. [5]

A4. Target efficiency ratio

\begin{tabular}{|c|c|c|}
\hline \multirow{2}{*}{ Type } & $(\mathrm{CC})$ & $\begin{array}{c}\text { (EER) } \\
\text { W/W }\end{array}$ \\
\hline \multirow{2}{*}{ unitary } & $\mathrm{W}$ & 2.9 \\
\hline \multirow{3}{*}{ Split } & & 3.2 \\
\cline { 2 - 3 } & $4500<C C \leqslant 7100$ & 3.1 \\
\cline { 2 - 3 } & $7100<C C \leqslant 14000$ & 3.0 \\
\hline
\end{tabular}

\subsection{Reconstruction of heating network}

Setting up a special device in heating network contributes to reducing the energy consumption of the network operation. Replace the damaged pipe and valve components.

\subsection{Transformation of "ping changed slope"}

Changing key parts and multilayer residential building of flat roof on both sides of main street road the into pitched roof buildings, and then combining with the exterior wall transformation, making external facade in white wash, which will improve the look of the residential building energy-saving performance and visual effects for the target.

Putting light steel structure into brick structure on the roof to the slope roof building can save $0.61 \mathrm{~kg}$ standard coal every square meter all the year round. With building area of $5000 \mathrm{~m}^{2}$ calculation, the year of standard coal saving is about 3.05 t. [3] 
At present, the energy situation in China is more than $80 \%$ of new housing construction: for high energy consuming buildings, both buildings $95 \%$ is high-energy buildings. [2]

\section{Conclusion}

Therefore, building energy conservation and promote the implementation of energy-saving construction are not only the need to implement the national energy strategy and the strategy of sustainable development, but also the need to improve the people's living quality, and Changchun City on the transformation of existing buildings energy-saving precisely meet the needs of the development of China's building energy efficiency, reduce energy consumption, and improve the building energy use rate.

\section{Acknowledgements}

Jilin Provincial Department of Education, "12th Five-Year Plan” Social science research. No. 2012-210

\section{References}

[1] "Design standard for energy efficiency of residential buildings in hot summer and cold winter area" $[\mathrm{M}]$, Institute of the Ministry of Construction Standards and Norms. Beijing, China Architecture \& Building Press, 2001.

[2] Tu fengxiang, "building energy conservation", pp 34, [M], Beijing, China Architecture \& Building Press, 2001.

[3] Zhaojian, "Building energy saving engineering design manual" [k], Beijing, Economic Science Press, 2005.

[4] China Institute of building standard design and research "Exterior insulation construction", 02J121-1[S], Beijing, Ministry of construction of the people's Republic of China, 2002.

[5] Jiyuan, Fang yongban, Northern Jiangsu area energy saving reform of the existing public building institute [I], industrial building, 2010. 